Research article

\title{
An index system constructed for ecological stress assessment of the coastal zone: A case study of Shandong, China
}

\author{
$\mathrm{Lu} \mathrm{Yu}^{\mathrm{a}, \mathrm{b}}$, Xiaoqing $\mathrm{Wu}^{\mathrm{c}}$, Xilai Zheng ${ }^{\mathrm{a}, \mathrm{b}, *}$, Tianyuan Zheng, ${ }^{\mathrm{d}, \mathrm{*}, *}$, Jia Xin ${ }^{\mathrm{a}, \mathrm{b}}$, Marc Walther ${ }^{\mathrm{d}, \mathrm{e}}$ \\ ${ }^{a}$ Shandong Provincial Key Laboratory of Marine Environment and Geological Engineering, Ocean University of China, Qingdao, 266100, China \\ ${ }^{\mathrm{b}}$ Key Lab of Marine Environmental Science and Ecology, Ministry of Education, College of Environmental Science and Engineering, Ocean University of China, Qingdao, \\ 266100, China \\ ${ }^{\mathrm{c}}$ Yantai Institute of Coastal Zone Research, Chinese Academy of Sciences, Yantai, 264003, China \\ ${ }^{\mathrm{d}}$ Helmholtz Centre for Environmental Research - UFZ, Permoserstraße 15, 04318, Leipzig, Germany \\ ${ }^{\mathrm{e}}$ Applied Environmental Systems Analysis, Dresden University of Technology, Germany
}

\section{A R T I C L E I N F O}

\section{Keywords:}

Coastal zone

Ecological stress

Index system

Shandong

\begin{abstract}
A B S T R A C T
Coastal zones, which have high ecological value and environmental function and play a key role in human development, face intense ecological stress from human activities. This study constructed an assessment index system for coastal zones and proposed a coastal ecological stress index (CESI) model. This method was then applied to the Shandong coastal zone. The results showed an increase in ecological stress from 2001 to 2016 and implied a further growth trend. The stress caused by terrigenous pollution was the most prominent, with the ecological stress index showing significant spatial difference. Qingdao exerted the highest ecological stress on the population and economy, while Yantai showed the highest stress on the coastal index. The CESI model effectively reflects the temporal and spatial characteristics of the coastal ecological stress and provides a theoretical basis for the management of different regions.
\end{abstract}

\section{Introduction}

The coastal zone, located at the boundary of continental land and sea, provides abundant resources for human development, and is the most active and concentrated area of human activity (Reguero et al., 2018). According to the United Nations Conference on Environment and Development (1992), 60\% of the world population lives within about 100\&\#x202F;km from the coastline. However, with population expansion, economic development, and over-exploitation, the coastal zones are facing problems of decline in biodiversity, coastal habitat loss, water quality degradation, and species invasion (Sala et al., 2000; Kappel, 2005; Lotze et al., 2006). Human activity such as coastal development and pollution have considerably increased the stress on the coastal ecosystem (Halpern et al., 2008, 2012; Song et al., 2016). Therefore, the ecological stress on coastal zones needs to be quantitatively evaluated for the development of a coastal ecosystem.

Ecological stress refers to the external factors endangering the ecosystem's stability, with human activity considered the driving stress factor in the ecosystem (Chen et al., 2005; Reguero et al., 2018).
Current studies on ecological stress mainly focus on the carrying capacity of the ecological environment, especially on the theoretical framework based on the pressure-state-response (PSR; Wei et al., 2014; Wang and $\mathrm{Xu}, 2015)$ and driver-pressure-state-impact-response (DPSIR; IMPRESS, 2002; Borja et al., 2006; Liu et al., 2018). However, the index system and methods of these studies focus mainly on evaluating the integrity of the ecosystem than on assessing the ecological stress (Tang et al., 2018). Additionally, the stress indicators are relatively simple and more targeted, and so cannot fully reflect the stress of coastal zones (Levrel et al., 2009; Song et al., 2016).

Some scholars have recently studied the stress in specific areas, such as the grassland ecosystem (Feng et al., 2009), heavily industrialized cities (Wu et al., 2012), tourism areas (Michailidou et al., 2015), river stretches (Villanueva and Ibarra, 2016), and estuarine macrofaunal communities (Ellis et al., 2015). Some recent studies have additionally proposed different indexes and methods, such as the integrated system dynamics model (Wang et al., 2014), marine ecological carrying capacity (MECC) index system (Ma et al., 2017), energy ecological footprint method (Peng et al., 2018), tourism environmental composite

\footnotetext{
* Corresponding author. Shandong Provincial Key Laboratory of Marine Environment and Geological Engineering, Ocean University of China, Qingdao, 266100, China.

** Corresponding author. Helmholtz Centre for Environmental Research - UFZ, Permoserstraße 15, 04318 Leipzig, Germany.

E-mail addresses: zhxilai@ouc.edu.cn (X. Zheng), ichbinzty@gmail.com (T. Zheng).
} 
indicator (TECI; Michailidou et al., 2015), and abundance biomass comparison (ABC) index (Villanueva and Ibarra, 2016). However, few studies quantitatively analyse coastal ecological stress (Song et al., 2016; Ma et al., 2017). Furthermore, a general index and standard are required for assessing coastal ecological stress, but they have not been formulated, and pursuing their development is one of the focuses for future research.

Thus, this study constructs an index system and establishes a coastal ecological stress index (CESI) model to assess the ecological stress attributed to human activities. The study also provides a theoretical basis for the comprehensive management of coastal zones by analysing the ecological stress characteristics, trends, and spatiality in the Shandong province.

\section{Methods}

\subsection{Establishing the index system}

A scientific and reasonable index framework is the key to assessing coastal ecological stress. Indicator selection should follow scientific, quantitative, comprehensive, and feasible principles (Valenti et al., 2018). Under these principles, construction of an index system consists of the following three steps: (1) establish a preliminary index system, (2) screen the indicators, and (3) optimize the index system.

Finally, the evaluation index system is constructed using the primary and secondary indexes shown in Table 1 . The primary index consists of the population, economic, terrestrial pollution, and coastal aspects. The secondary index includes 13 typical indicators. The index framework is applicable to coastal areas and is adjusted according to the regional characteristics and data availability.

\subsection{Indicator standardization}

Because of the difference between the indicator magnitude and units, the original data are standardized for comparison, with the standard value between 0 and 1 . The extreme standard method takes the form of the following equation:

$\mathrm{X}_{k}=\frac{x_{k}-\min \left(x_{k}\right)}{\max \left(x_{k}\right)-\min \left(x_{k}\right)}$

where $X_{k}$ is the standard value, $x_{k}$ is the original value, and max $\left(x_{k}\right)$ and min $\left(x_{k}\right)$ are the maximum and minimum values of indicator $x_{k}$, respectively.

\subsection{Weight determination using the analytic hierarchy process (AHP) model}

Weight is the quantitative allocation of coefficients based on the indicator's importance. The AHP is a multi-objective decision analysis method combining the qualitative and quantitative criteria (Saaty, 1977). It is considered more consistent with the actual evaluation system, and is widely applied to determine weights (Zhang et al., 2014; Song et al., 2016; Wang et al., 2017). The AHP consists of two key steps: construct a judgment matrix and consistency check (Tian et al., 2013; Song et al., 2016; Kundu et al., 2017).

\section{(1) Construct a judgment matrix.}

The judgment matrix element value was determined by the expert scoring method. Twenty-five experts were invited to complete the questionnaire and scored the relative importance of the indicators according to 9-point scale (Saaty, 1990). These experts included professors from university and research institute and senior personnel from the municipal environmental protection bureau and Shandong Provincial Oceanic and Fishery Department.

After the questionnaire, the scores with large deviation were removed and geometric mean method was used to calculate the final scores. Then the judgmental matrix was constructed according to the mean score and denoted as A. Each entry $a_{i j}$ of the judgmental matrix was formed by comparing the row element $A_{i}$ with the column element $A_{j}$.

$A=\left(a_{i j}\right)\left(\mathrm{a}_{i j}>0, \mathrm{a}_{i j}=1 / \mathrm{a}_{i j}\right)$,

where $i \& \# x 202 F ;=\& \# x 202 F ; 1,2 \ldots$, the number of layers; and $j \&$ $\# \mathrm{x} 202 \mathrm{~F} ;=$ \&\#x202F;1, 2 ..., the number of elements.

The eigenvector of the matrix can be calculated using the squareroot method as follows (Tian et al., 2013):

$M_{i}=\prod_{j=1}^{n} a_{i j}$

$\overline{w_{i}}=\sqrt[n]{M_{i}}$

$w_{i}=\bar{w}_{i} / \sum_{j=1}^{n} \bar{w}_{j}(i=1,2 \ldots, n)$

where $w_{\mathrm{i}}$ is the eigenvector, and $\mathrm{n}$ is the matrix order.

(2) Consistency check.

However, decisions about the relative importance of different indicators are subjective, which made it essential to do the consistency check. The consistency ratio (CR) determines the judgmental matrix's consistency:

$\mathrm{CR}=\mathrm{CI} / \mathrm{RI}$

where $\mathrm{CI}$ represents the consistency and RI is the random consistency index.

The CI values can be calculated as follows:

Table 1

The index system and weight.

\begin{tabular}{|c|c|c|c|c|}
\hline Index name & Primary index & Secondary index & Primary weight & Secondary weight \\
\hline \multirow[t]{13}{*}{ Coastal ecological stress } & \multirow[t]{2}{*}{ Population } & Density of population $\left(\mathrm{x}_{1}\right)$ & \multirow[t]{2}{*}{0.06123} & 0.33333 \\
\hline & & Natural growth rate $\left(\mathrm{x}_{2}\right)$ & & 0.66667 \\
\hline & \multirow[t]{3}{*}{ Economy } & Per capita GDP $\left(\mathrm{x}_{3}\right)$ & \multirow[t]{3}{*}{0.26483} & 0.29696 \\
\hline & & GDP growth rate $\left(\mathrm{x}_{4}\right)$ & & 0.53961 \\
\hline & & Domestic tourism revenue $\left(\mathrm{x}_{5}\right)$ & & 0.16342 \\
\hline & \multirow[t]{5}{*}{ Terrestrial pollution } & Year-end stock of large livestock $\left(\mathrm{x}_{6}\right)$ & \multirow[t]{5}{*}{0.56692} & 0.08016 \\
\hline & & Consumption of chemical fertilizers $\left(\mathrm{x}_{7}\right)$ & & 0.12704 \\
\hline & & Consumption of pesticides $\left(\mathrm{x}_{8}\right)$ & & 0.05431 \\
\hline & & Volume of industrial wastewater discharged $\left(\mathrm{x}_{9}\right)$ & & 0.28812 \\
\hline & & Volume of domestic wastewater discharged $\left(\mathrm{x}_{10}\right)$ & & 0.45037 \\
\hline & \multirow[t]{3}{*}{ Coastal } & Total ocean fishing amount $\left(\mathrm{x}_{11}\right)$ & \multirow[t]{3}{*}{0.10702} & 0.12196 \\
\hline & & Area of cultured seawater $\left(\mathrm{x}_{12}\right)$ & & 0.55842 \\
\hline & & Volume of freight handled in coastal ports $\left(\mathrm{x}_{13}\right)$ & & 0.31962 \\
\hline
\end{tabular}


Table 2

RI values.

\begin{tabular}{lllllllll}
\hline $\mathrm{n}$ & 2 & 3 & 4 & 5 & 6 & 7 & 8 & 9 \\
\hline $\mathrm{RI}$ & 0 & 0.58 & 0.90 & 1.12 & 1.24 & 1.32 & 1.41 & 1.45 \\
\hline
\end{tabular}

$\mathrm{CI}=\left(\lambda_{\max }-n\right) /(n-1)$

$\lambda_{\max }=\sum_{i=1}^{n} \frac{(A w)_{i}}{n w_{i}}$

where $\lambda_{\max }$ is the largest matrix eigenvalue, and $\mathrm{n}$ is the matrix order.

The random index (RI) values for different matrixes are shown in Table 2 (Saaty, 1980).

If the $\mathrm{CR}$ is 0.10 or less, the matrix meets the consistency requirement and the eigenvector is the weight; otherwise, the judgments must be re-adjusted. The weight calculations are shown in Table 1.

\subsection{CESI model}

To evaluate the coastal ecological stress caused by human activity, the study proposed a coastal ecological stress index (CESI) model. The basic principle of the CESI model is to make a linear weighting of indicators based on weight. The CESI is designed to be a scale of 0-1, where the closer the CESI to 1 , the greater is the ecological stress.

The CESI consists of the following four sub-indexes: the population index $(P I)$, economic index $(E I)$, terrestrial pollution index (TPI), and coastal index $(C I)$. The model is formulated as follows:

$\mathrm{CESI}=\mathrm{PI} \times P_{1}+\mathrm{EI} \times P_{2}+\mathrm{TPI} \times P_{3}+\mathrm{CI} \times P_{4}$

where $P_{1}, P_{2}, P_{3}$, and $P_{4}$ are the weights of PI, EI, TPI and CI, respectively; that is, the primary weight.

The sub-indexes are calculated as follows:

$\mathrm{PI}=\sum_{e=1}^{E} P I_{e} \times W_{e}$

$\mathrm{EI}=\sum_{f=1}^{F} E I_{f} \times W_{f}$

$\mathrm{TPI}=\sum_{g=1}^{G} T P I_{g} \times W_{\mathrm{g}}$

$\mathrm{CI}=\sum_{h=1}^{H} C I_{h} \times W_{h}$

where $P I_{e}$ and $W_{e}$ denote the standardized value and weight of the PI ( $e$ $\& \# \mathrm{x} 202 \mathrm{~F} ;=\& \# \mathrm{x} 202 \mathrm{~F} ; 1,2 \ldots, E) ; E I_{f}$ and $W_{f}$ denote the standardized value and weight of the EI $(f \& \# \mathrm{x} 202 \mathrm{~F} ;=\& \# \mathrm{x} 202 \mathrm{~F} ; 1,2 \ldots, F) ; T P I_{g}$ and $W_{g}$ denote the standardized value and weight of the TPI $(g \& \# \mathrm{x} 202 \mathrm{~F} ;=\&$ $\#$ x202F;1, $2 \ldots, G)$; and $C I_{h}$ and $W_{h}$ denote the standardized value and weight of the CI ( $\& \& \# \times 202 \mathrm{~F} ;=\& \# \mathrm{x} 202 \mathrm{~F} ; 1,2 \ldots, H)$, respectively.

\section{Case study}

\subsection{Study area}

The Shandong province is an important coastal province in China with a coastline of more than $3000 \& \# x 202 \mathrm{~F} ; \mathrm{km}$ and accounting for about one-sixth of the national coastline. The seas in this province are the Bohai and Yellow seas. The Gross Ocean Product (GOP) of the Shandong province in 2015 was 1.2 trillion yuan, accounting for $19 \%$ of its GDP. Thus, the coastal zones are witnessing economic growth, but the coastal ecological environment is facing a threat from human activities due to rapid economic development.

A coastal zone covers the area extending up to a certain distance
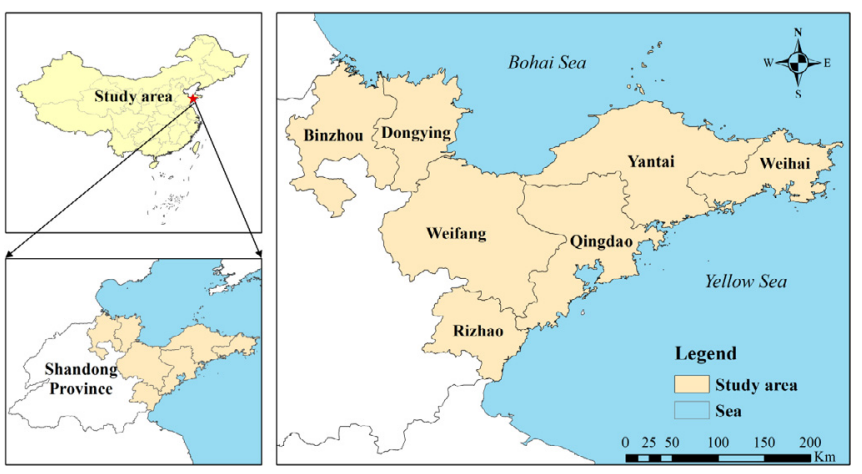

Fig. 1. Location of the Shandong coastal area, China.

from the coastline, including the land and offshore waters. Although there is no standard definition for the boundaries of a coastal zone, they are usually determined according to the actual research and management requirements (Zhang et al., 2015). Given the availability of data and feasibility of the study, the coastal zone in this study includes the prefecture-level cities having a coastline. Specifically, the coastal zone considered in this study include the following cities: Binzhou, Dongying, Weifang, Yantai, Weihai, Qingdao, and Rizhao (Fig. 1). In regard to the geographical space, the study area corresponds with the 'Blue Economic Zone of the Shandong peninsula', an important part of the national marine development and regional coordinated development strategy.

\subsection{Data sources}

The data of 13 indicators were collected from the Shandong and China marine statistical yearbooks; the tourism data were extracted from the Shandong tourism statistics online government integrated platform. The parts of data are shown in Table 3.

\subsection{Results}

\subsubsection{Comprehensive analysis of coastal stress}

Using the above methods, this study calculated the PI, EI, TPI, CI, and CESI of the Shandong coastal zone (Fig. 2). The evaluation value is the sub-index multiplied by the weight.

From Fig. 2, the CESI of the Shandong coastal zone showed a rising trend from 2001 to 2016, except when it slightly declined in 2009 and 2016. The decline was mainly due to the fall in economic stress in 2009 and terrestrial pollution emissions in 2016 .

Estimates of the four sub-indexes showed that terrestrial pollution contributed the most towards coastal ecological stress, followed by economic development and coastal activity, with the least stress coming from population. Moreover, the TPI witnessed an apparent increase, with the change in trend roughly the same as that in CESI, while PI, EI, and CI recorded a slight increase in fluctuation.

\subsubsection{Analysis of CESI in different cities}

The study integrated all the ecological stress evaluation values into Geographic Information System (GIS), and carried out spatial analysis by applying the GIS quantitative classification function.

Because the volume of the freight handled in coastal ports is hard to allocate to every city, this indicator is not considered. The CI included the total ocean fishing amount and the area of cultured seawater, weighing 0.25 and 0.75 , respectively. Additionally, because of lack of some regional data prior to 2003 , the time series of the spatial analysis is adjusted to 2003-2016.

According to the overall layout of the study area shown in Fig. 3, the CESI of the central region represented by Weifang and Qingdao is relatively large, while that of the surrounding region is relatively small. 
Table 3

Data of the Shandong coastal zone.

\begin{tabular}{|c|c|c|c|c|c|c|c|c|c|c|}
\hline \multirow[t]{2}{*}{ Indicators } & \multirow[t]{2}{*}{ Unit } & \multicolumn{9}{|l|}{ Years } \\
\hline & & 2001 & 2003 & 2005 & 2007 & 2009 & 2011 & 2013 & 2015 & 2016 \\
\hline $\mathrm{x}_{1}$ & Person $/ \mathrm{km}^{2}$ & 467 & 470 & 476 & 481 & 484 & 488 & 490 & 495 & 499 \\
\hline $\mathrm{x}_{2}$ & $\%$ & 2.98 & 2.48 & 5.52 & 5.61 & 3.39 & 3.64 & 3.96 & 3.97 & 8.13 \\
\hline $\mathrm{x}_{3}$ & $10^{6}$ yuan $^{\mathrm{a}}$ & 146 & 193 & 284 & 398 & 511 & 672 & 804 & 907 & 958 \\
\hline $\mathrm{x}_{4}$ & $\%$ & 12.02 & 18.38 & 21.73 & 18.56 & 8.82 & 14.43 & 8.79 & 6.29 & 6.46 \\
\hline$x_{5}$ & $10^{8}$ yuan & 264 & 303 & 523 & 841 & 1226 & 1805 & 2503 & 3251 & 3696 \\
\hline $\mathrm{x}_{6}$ & $10^{3}$ head & 3236 & 3297 & 3247 & 2165 & 2053 & 2047 & 1823 & 1550 & 1351 \\
\hline $\mathrm{x}_{7}$ & $10^{3}$ tonne $^{\mathrm{a}}$ & 1733 & 1790 & 1909 & 2040 & 1876 & 1797 & 1786 & 1776 & 1758 \\
\hline $\mathrm{x}_{8}$ & $10^{3}$ tonne & 71 & 75 & 77 & 80 & 78 & 76 & 73 & 67 & 65 \\
\hline$x_{9}$ & $10^{6}$ tonne & 419 & 442 & 552 & 633 & 706 & 829 & 850 & 874 & 763 \\
\hline$x_{10}$ & $10^{6}$ tonne & 493 & 502 & 565 & 712 & 905 & 1091 & 1283 & 1455 & 1386 \\
\hline $\mathrm{x}_{11}$ & $10^{3}$ tonne & 2511 & 2421 & 2421 & 2452 & 2450 & 2512 & 2428 & 2751 & 2822 \\
\hline $\mathrm{x}_{12}$ & $10^{3} \& \# \times 202 \mathrm{~F} ; \mathrm{ha}$ & 290 & 358 & 407 & 406 & 441 & 512 & 547 & 563 & 562 \\
\hline $\mathrm{x}_{13}$ & $10^{6}$ tonne & 193 & 256 & 384 & 575 & 731 & 962 & 1181 & 1342 & 1429 \\
\hline
\end{tabular}

a Yuan is the currency unit of China; 1 tonne\&\#x202F;=\&\#x202F;1000\&\#x202F;kg.

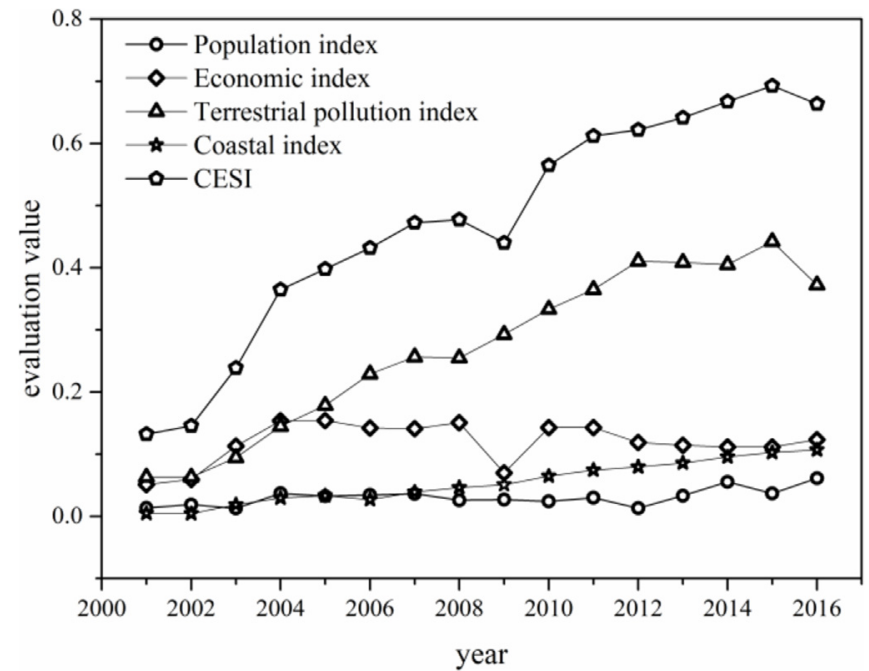

Fig. 2. Ecological stress evaluation results and trends in the Shandong coastal zone.

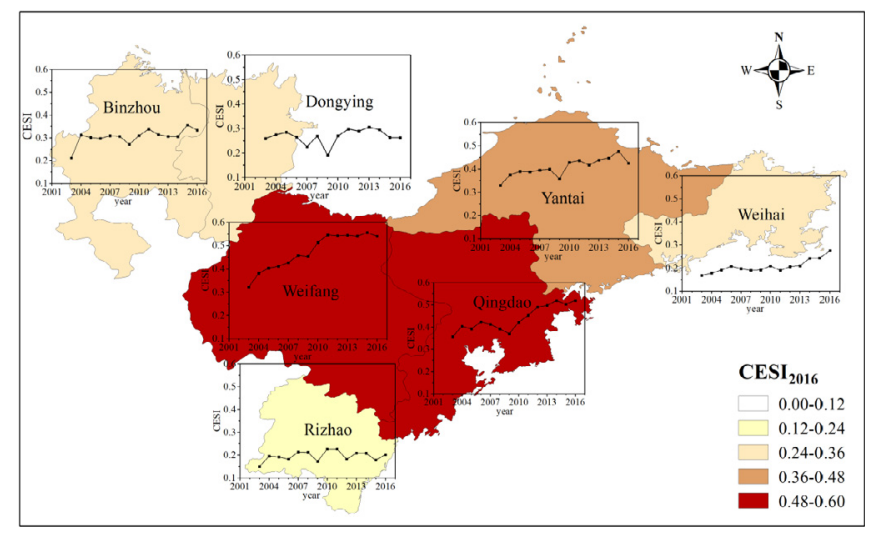

Fig. 3. CESI trends in different cities.

From the CESI trends in different regions, the stress of Weifang increased at a rapid pace, by $68 \%$ from 2003 to 2016 .

\subsubsection{Sub-index analysis in different cities}

The stress characteristics of the sub-indexes in different cities for 2016 shown in Fig. 4 reveal significant spatial differences in Shandong's coastal ecological stress.

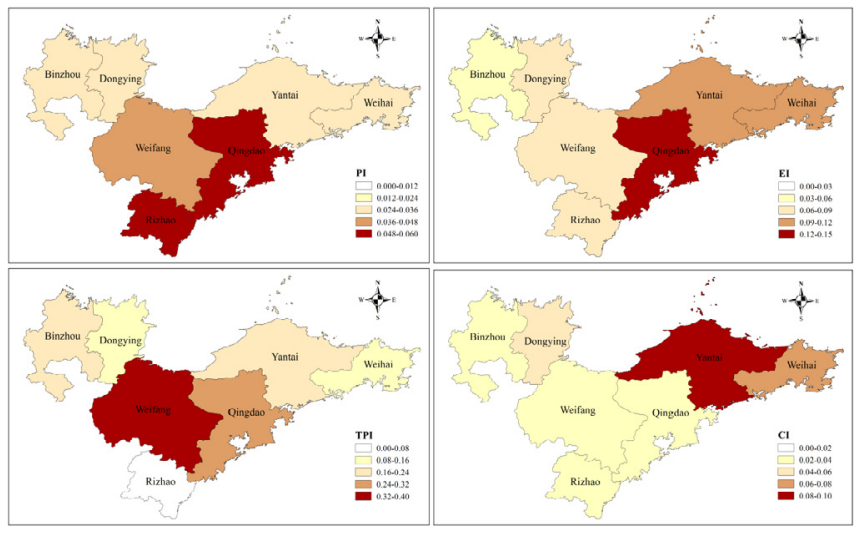

Fig. 4. Spatial distribution of sub-indexes in different cities in 2016. The PI, EI, TPI, and $\mathrm{CI}$ values include the weight.

The analyses of the four sub-indexes are as follows. First, in terms of PI, Qingdao and Rizhao exerted the highest stress on the coastal zones, with the lowest stress coming from Yantai. Second, Qingdao, as one of the first open coastal cities in China and the leading city in the Blue Economic Zone of the Shandong peninsula, showed strong economic strength, especially in the booming tourism industry. Therefore, in terms of the EI sub-index, Qingdao exerted the highest ecological stress on the coastal zone. Third, in terms of TPI, Weifang exerted the highest stress, mainly due to its considerable wastewater emissions. Fourth, in regard to the CI, the ecological stress of Yantai was very prominent, attributed mainly to its long coastline, large-scale aquaculture area, and marine fishing.

\section{Discussion}

An evaluation of the coastal ecological stress in Shandong province shows that the CESI approach is scientific and feasible, with more intuitive and spatial results when combining GIS. The ecological stress based on CESI may be closer to reality compare with other researches, because its index system is more comprehensive and targeted. For example, our evaluation index system consisted of the population, economic, terrestrial pollution, and coastal aspects, while the comprehensive eco-environment stress (CES) index (Wang et al., 2016) which was carried out in Bohai coastal area, only include population and pollutant emission.

In an overall analysis of the Shandong province CESI, the ecological stress increased significantly, with the stress due to terrestrial emissions most prominent. Therefore, the most effective measures to reduce 
ecological stress would be to reduce the discharge of wastewater and pollutants and to promote the establishment of energy conservation and emission reduction projects.

For the quantitative and spatial evaluation of ecological stress, the results can better guide the formulation of measures and make the measures more targeted, while few studies quantitatively analyse coastal ecological stress (Zou et al., 2004; Ma et al., 2017). The ecological stress in different cities of Shandong Province showed the central region was identified as the key area requiring the mitigation of coastal stress. According to local stress characteristics, different cities should take different measures to promote the healthy development of the coastal ecosystem. For example, Weifang should strictly control the emission of land-sourced pollutants, while Yantai should reasonably plan the area and site of cultured seawater and strictly control the discharge standards of aquaculture wastewater.

The study also shows the need to continue to explore and improve the methods for assessing the coastal ecological stress. First, the CESI system needs to be further improved and the problem of obtaining the coastal and marine index solved. Second, it is difficult to estimate the influence of human activities on the coastal ecology as well as difficult or impossible to quantify some indicators, thus increasing the complexities of calculating the ecological stress in coastal zones. Therefore, future studies need to focus on the development of an index system and quantitative methods. The complexity of interaction between human activities and coastal ecological environment can even be solved by developing mathematical models (Papadimitriou, 2013).

\section{Conclusion}

This study constructed an index system and proposed a coastal ecological stress index (CESI) model. We chose the Shandong coastal zone as a case study and the evaluation results confirmed the validity of CESI in theory and practice. The conclusions drawn from this study were as follows. (1) The Shandong province CESI increased significantly, with the stress due to terrestrial emissions most prominent. (2) The CESI was relatively higher in the central regions, with the surrounding areas showing lower levels. (3) The sub-indexes showed significant spatial differences. The results of the study could provide a theoretical reference for the comprehensive management of coastal zones.

This study provided a useful example about how to evaluate ecological stress in coastal zone. The selection rules and weight determination method of index system have universality to a certain extent, and the CESI model can be referenced for assessment of ecological stress in other coastal regions. When this model is used for the research of other regions, the index and weight could be adjusted according to the specific regional characteristics and data availability.

\section{Acknowledgements}

This work was supported by the National Natural Science Foundation of China (grant number 41731280), the National Key Research and Development Program of China (grant number 2016YFC0402810), and the Chinese Academy of Sciences Key Deployment Project (grant number KZZD-EW-14).

\section{References}

Borja, A., Galparsoro, I., Solaun, O., Muxika, I., Tello, E.M., Uriarte, A., Valencia, V., 2006. The European Water Framework Directive and the DPSIR, a methodological approach to assess the risk of failing to achieve good ecological status. Estuar. Estuar. Coast. Shelf Sci. 66 (1-2), 84-96. https://doi.org/10.1016/j.ecss.2005.07.021.

Chen, C.H., Liu, W.L., Liaw, S.L., Yu, C.H., 2005. Development of a dynamic strategy planning theory and system for sustainable river basin land use management. Sci. Total Environ. 346 (1-3), 17-37. https://doi.org/10.1016/j.scitotenv.2004.12.057.

Ellis, J.I., Hewitt, J.E., Clark, D., Taiapa, C., Patterson, M., Sinner, J., Hardy, D., Thrush, S.F., 2015. Assessing ecological community health in coastal estuarine systems impacted by multiple stressors. J. Exp. Mar. Biol. Ecol. 473, 176-187. https://doi.org/ 10.1016/j.jembe.2015.09.003

Feng, Y.Z., Yang, G.H., Wang, D.X., Hu, L.W., 2009. Ecological stress in grassland ecosystems in source regions of Yangtze, Yellow and Lancang Rivers over last 40 years. Acta Ecol. Sin. 29 (1), 492-498.

Halpern, B.S., Walbridge, S., Selkoe, K.A., Kappel, C.V., Micheli, F., D'Agrosa, C., Bruno, J.F., Casey, K.S., Ebert, C., Fox, H.E., Fujita, R., Heinemann, D., Lenihan, H.S., Madin, E.M., Perry, M.T., Selig, E.R., Spalding, M., Steneck, R., Watson, R., 2008. A global map of human impact on marine ecosystems. Science 319 (5865), 948-952. https:// doi.org/10.1126/science.1149345.

Halpern, B.S., Longo, C., Hardy, D., McLeod, K.L., Samhouri, J.F., et al., 2012. An index to assess the health and benefits of the global ocean. Nature 488, 615-620. https://doi. org/10.1038/nature11397.

IMPRESS, 2002. Guidance for the analysis of pressures and impacts in accordance with the Water Framework Directive. In: Common Implementation Strategy Working Group 2.1. Office for Official Publications of the European Communities, pp. 156. Retrieved on July 12, 2005 from. http://forum.europa.eu.int/Public/irc/env/wfd/ library ISBN: 92-894-5123.

Kappel, C.V., 2005. Losing pieces of the puzzle: threats to marine, estuarine, and diadromous species. Front. Ecol. Environ. 3 (5), 275-282. https://doi.org/10.1890/ 1540-9295(2005)003[0275:LPOTPT]2.0.CO;2.

Kundu, S., Khare, D., Mondal, A., 2017. Landuse change impact on sub-watersheds prioritization by analytical hierarchy process (AHP). Ecol. Inf. 42, 100-113. https:// doi.org/10.1016/j.ecoinf.2017.10.007.

Levrel, H., Kerbiriou, C., Couvet, D., Weber, J., 2009. OECD pressure-state-response indicators for managing biodiversity: a realistic perspective for a French biosphere reserve. Biodivers. Conserv. 18 (7), 1719-1732. https://doi.org/10.1007/s10531008-9507-0.

Liu, X., Liu, H.T., Chen, J.C., Liu, T.W., Deng, Z.L., 2018. Evaluating the sustainability of marine industrial parks based on the DPSIR framework. J. Clean. Prod. 188, 158-170. https://doi.org/10.1016/j.jclepro.2018.03.271.

Lotze, H.K., Lenihan, H.S., Bourque, B.J., Bradbury, R.H., Cooke, R.G., Kay, M.C., Kidwell, S.M., Kirby, M.X., Peterson, C.H., Jackson, J.B., 2006. Depletion, degradation and recovery potential of estuaries and coastal seas. Science 312 (5781), 1806-1809. https://doi.org/10.1126/science.1128035.

Ma, P.P., Ye, G.Q., Peng, X., Liu, J.F., Qi, J.G., Jia, S.G., 2017. Development of an index system for evaluation of ecological carrying capacity of marine ecosystems. Ocean Coast Manag. 144, 23-30. https://doi.org/10.1016/j.ocecoaman.2017.04.012.

Michailidou, A.V., Vlachokostas, C., Moussiopoulos, N., 2015. A methodology to assess the overall environmental pressure attributed to tourism areas: a combined approach for typical all-sized hotels in Chalkidiki, Greece. Ecol. Indicat. 50, 108-119. https:// doi.org/10.1016/j.ecolind.2014.11.006.

Papadimitriou, F., 2013. Mathematical modelling of land use and landscape complexity with ultrametric topology. J. Land Use Sci. 8 (2), 234-254. https://doi.org/10.1080/ 1747423X.2011.637136.

Peng, W.J., Wang, X.M., Li, X.K., He, C.C., 2018. Sustainability evaluation based on the emergy ecological footprint method: a case study of Qingdao, China, from 2004 to 2014. Ecol. Indicat. 85, 1249-1261. https://doi.org/10.1016/j.ecolind.2017.12.020.

Reguero, B.G., Beck, M.W., Agostini, V.N., Kramer, P., Hancock, B., 2018. Coral reefs for coastal protection: a new methodological approach and engineering case study in Grenada. J. Environ. Manag. 210, 146-161. https://doi.org/10.1016/j.jenvman. 2018.01.024.

Saaty, T.L., 1977. A scaling method for priorities in hierarchical structures. J. Math Psychol. 15 (3), 234-281. https://doi.org/10.1016/0022-2496(77)90033-5.

Saaty, T.L., 1980. Fundamentals of Decision Making and Priority Theory with Analytical Hierarchical Process, vol. VI. RWS Publications University of Pittsburgh, Pittusburgh USA, pp. 3-95.

Saaty, T.L., 1990. How to make a decision: the analytic hierarchy process. Eur. J. Oper. Res. 48 (1), 9-26. https://doi.org/10.1016/0377-2217(90)90057-I.

Sala, O.E., Chapin, F.S., Armesto, J.J., Berlow, E., Bloomfield, J., Dirzo, R., HuberSanwald, E., Huenneke, L.F., Jackson, R.B., Kinzig, A., Leemans, R., Lodge, D.M., Mooney, H.A., Oesterheld, M., Poff, N.L., Sykes, M.T., Walker, B.H., Walker, M., Wall, D.H., 2000. Global biodiversity scenarios for the year 2100. Science 287 (5459), 1770-1774. https://doi.org/10.1126/science.287.5459.1770.

Song, D.M., Zang, L., Liu, C.X., Shi, X.F., Wu, H.S., 2016. Evaluation of geologic bearing capacity of coastal zones taking coastal area of Laizhou Bay as an example. Ocean Coast Manag. 134, 129-139. https://doi.org/10.1016/j.ocecoaman.2016.10.004.

Tang, D.H., Liu, X.J., Zou, X.Q., 2018. An improved method for integrated ecosystem health assessments based on the structure and function of coastal ecosystems: a case study of the Jiangsu coastal area, China. Ecol. Indicat. 84, 82-95. https://doi.org/10 1016/j.ecolind.2017.08.031.

Tian, W.J., Bai, J., Sun, H.M., Zhao, Y.G., 2013. Application of the analytic hierarchy process to a sustainability assessment of coastal beach exploitation: a case study of the wind power projects on the coastal beaches of Yancheng, China. J. Environ. Manag. 115, 251-256. https://doi.org/10.1016/j.jenvman.2012.11.015.

Valenti, W.C., Kimpara, J.M., Preto, B.D.L., Valenti, P.M., 2018. Indicators of sustainability to assess aquaculture systems. Ecol. Indicat. 88, 402-413. https://doi.org/10. 1016/j.ecolind.2017.12.068.

Villanueva, M.C., Ibarra, A.A., 2016. Assessing the ecological stress in a Garonne River stretch, southwest France. Ecol. Indicat. 67, 466-473. https://doi.org/10.1016/j. ecolind.2016.02.049.

Wang, S., Xu, L., Yang, F.L., Wang, H., 2014. Assessment of water ecological carrying capacity under the two policies in Tieling City on the basis of the integrated system dynamics model. Sci. Total Environ. 472, 1070-1081. https://doi.org/10.1016/j. scitotenv.2013.11.115.

Wang, T.X., Xu, S.G., 2015. Dynamic successive assessment method of water environment carrying capacity and its application. Ecol. Indicat. 52, 134-146. https://doi.org/10. 
1016/j.ecolind.2014.12.002.

Wang, D.C., Chen, W.G., Wei, W., Bird, B.W., Zhang, L.H., Sang, M.Q., Wang, Q.Q., 2016. Research on the relationship between urban development intensity and eco-environmental stresses in Bohai Rim coastal area, China. Sustainability 8 (4), 406. https://doi.org/10.3390/su8040406.

Wang, S.P., Li, K.Q., Liang, S.K., Zhang, P., Lin, G.H., Wang, X.L., 2017. An integrated method for the control factor identification of resources and environmental carrying capacity in coastal zones: a case study in Qingdao, China. Ocean Coast Manag. 142, 90-97. https://doi.org/10.1016/j.ocecoaman.2017.03.024.

Wei, C., Guo, Z.Y., Wu, J.P., Ye, S.F., 2014. Constructing an assessment indices system to analyze integrated regional carrying capacity in the coastal zones - a case in Nantong. Ocean Coast Manag. 93, 51-59. https://doi.org/10.1016/j.ocecoaman.2014.02.009.
Wu, M., Jia, F.R., Wang, L., Yao, Y., 2012. Evaluation of ecological pressure for the resource-based and heavy industrial city - a case study of Fushun, China. Proc. Environ. Sci. 13, 1165-1169. https://doi.org/10.1016/j.proenv.2012.01.110.

Zhang, Z., Lu, W.X., Zhao, Y., Song, W.B., 2014. Development tendency analysis and evaluation of the water ecological carrying capacity in the Sipping area of Jilin Province in China based on system dynamics and analytic hierarchy process. Ecol. Model. 275, 9-21. https://doi.org/10.1016/j.ecolmodel.2013.11.031.

Zhang, H.B., Luo, Y.M., Liu, X.H., Fu, C.C., 2015. Current researches and prospects on the coastal blue carbon. Scientia Sinica Terrae 45 (11), 1641-1648.

Zou, X.Q., Wang, Y., Wang, X.R., Ge, C.D., Niu, Z.S., 2004. Environmental stress and policy guidelines for environmental management of the Sanya coastal zone, Hainan Island, China. J. Coast Res. 43, 243-253. https://www.jstor.org/stable/25737039. 